\title{
Validation and sensitivity evaluation of the ID-GC-TOF-MS method for determination of PAHs in biogas
}

\author{
Taner Gokcen $\odot^{1 *}$, Gokhan Bilsel $\odot^{1}$, Tanıl Tarhan $\odot^{1}$, Ilker Un $\odot^{1}$, \\ Ahmet C. Goren $\odot^{1}$ and Adriaan van der Veen $\odot^{2}$
}

${ }^{I}$ TUBITAK UME, Chemistry Group, Organic Chemistry Laboratory, Gebze, Kocaeli, Türkiye

${ }^{2}$ Van Swinden Laboratorium (VSL), Thijsseweg 11 2629, JA Delft, The Netherlands

(Received September 20, 2017; Revised October 30, 2017; Accepted October 31, 2017)

\begin{abstract}
In this study, an ID-GC-TOF-MS method was developed and validated for polycyclic aromatic hydrocarbons (PAHs) by spiking solutions onto thermal desorption tubes using calibration solution loading ring (CSLR) apparatus and sweeping them by the aid of air stream. Once the method was developed and validated, the effect of other compounds found in biogas and biomethane was investigated by the same methodology used in method development by using a gravimetrically prepared biogas mixture consisting of $45 \%$ methane, $40 \%$ carbon dioxide and $15 \%$ nitrogen. There are standard reference methods for measurements of PAHs in air but there was no available standard method for PAHs in biogas and biomethane yet. This study provides a basis for the future studies to develop a standard method. Data obtained through this study showed that present method is not affected by the compounds found in biogas that are not present in other matrices such as ambient air.
\end{abstract}

Keywords: PAH; biogas; biomethane; thermal desorption; isotope dilution; GC-TOF-MS. C 2017 ACG Publications. All rights reserved.

\section{Sample Source}

Polycyclic aromatic hydrocarbon (PAH) calibration solutions of consisting benzo[a]anthracene, benzo[a]pyrene and naphthalene were prepared from individual stock solutions that were prepared gravimetrically from high purity solid standards. Purities of solid standards were determined by quantitative nuclear magnetic resonance (qNMR) purity assessment protocol developed in TUBITAK UME [1].

\section{Previous Studies}

Biogas is a valuable renewable energy produced from anaerobic digestion of sewage sludge, commercial composting, animal manure, residue landfill, waste biogasification and agro-zootechnical digestion in mesophilic $\left(35^{\circ} \mathrm{C}\right)$ and thermophilic $\left(55^{\circ} \mathrm{C}\right)$ conditions [2-4]. The process of biogas production takes place in four steps; hydrolysis, acidification, formation of acetic acid and formation of methane. Raw biogas comprise methane (40-70\%), carbon dioxide (30-45\%), nitrogen $(0-15 \%)$ and inorganic and organic contaminants [2]. Upgraded biogas, known as biomethane, contains at least $95 \%$ methane and less than $2.5 \%$ carbon dioxide.

\footnotetext{
* Corresponding author:E-mail: taner.gokcen@tubitak.gov.tr; Phone:+90 26267950 00; Fax:+90 2626795001
} 
Biogas and biomethane may contain a broad spectrum of hazardous organic compounds for human health. These hazardous organic compounds can be subdivided into two major groups as polycyclic aromatic hydrocarbons and volatile organic compounds (VOCs) [3,5].

Polycyclic aromatic hydrocarbons (PAHs) are categorized as a huge group of compounds consist of over 100 different chemicals that are known to be formed via incomplete combustion of organic matter at high temperatures during industrial processes, vehicle exhausts, waste incineration, domestic heating and also naturally such as by forest fires. They are ubiquitous in the environment and their structure is composed of two or more fused benzene rings in linear, angular or cluster arrangements. Due to their mutagenicity, carcinogenicity and amount of them found in the environment led to some of them being selected as priority pollutants (e.g., 16 PAHs) by EU and US Enviromental Protection Agency (EPA). In Europe, ambient air legislation targets benzo[a]pyrene (with an annual limit value of $1 \mathrm{ng} / \mathrm{m}^{3}$ ) because this compound carries highest toxic load (defined as concentration multiplied by toxicity) of any airbone PAH [6]. For biogas, there is no available legislation defined for the levels of PAHs yet.

Because of their thermally stable structure, PAHs generally exhibit a high melting point, a high boiling point and a low vapour pressure. Consequently, lighter PAHs tend to be preferentially enriched in the gas phase, while the heavier ones show almost complete association with particles [6]. Physicochemical properties of 16 priority pollutant PAHs are given in Table 1 below:

Table 1. Physico-chemical properties of priority pollutant PAHs.

\begin{tabular}{|c|c|c|c|c|c|c|}
\hline $\begin{array}{l}\text { PAHs } \\
\end{array}$ & Formula & $\begin{array}{l}\text { Number } \\
\text { of rings }\end{array}$ & $\begin{array}{l}\text { Molecular } \\
\text { Weight }\end{array}$ & $\begin{array}{l}\text { Melting } \\
\text { Point } \\
\left({ }^{\circ} \mathrm{C}\right)\end{array}$ & $\begin{array}{l}\text { Vapour } \\
\text { Pressure at } \\
25 \quad{ }^{\circ} \mathrm{C} \quad(\mathrm{mm} \\
\mathrm{Hg})\end{array}$ & $\begin{array}{l}\text { Solubility in } \\
\text { water at } 25 \\
{ }^{\circ} \mathrm{C}(\mu \mathrm{g} / \mathrm{L})\end{array}$ \\
\hline Benzo[ghi]perylene & $\mathrm{C}_{22} \mathrm{H}_{12}$ & 6 & 276.4 & 273 & $1.03 \times 10^{-10}$ & 0.26 \\
\hline Indeno[1,2,3-cd]pyrene & $\mathrm{C}_{22} \mathrm{H}_{12}$ & 6 & 276.3 & 163.6 & $1 \times 10^{-11}$ & 6.2 \\
\hline Dibenz[a,h]anthracene & $\mathrm{C}_{22} \mathrm{H}_{14}$ & 5 & 278.3 & 262 & $1 \times 10^{-10}\left(20^{\circ} \mathrm{C}\right)$ & 0.5 \\
\hline Benzo[a]pyrene & $\mathrm{C}_{20} \mathrm{H}_{12}$ & 5 & 252.3 & 179 & $5.6 \times 10^{-9}$ & 2.3 \\
\hline Benzo[k]fluoranthene & $\mathrm{C}_{20} \mathrm{H}_{12}$ & 5 & 252.3 & 215.7 & $9.59 \times 10^{-11}$ & 0.76 \\
\hline Benzo[b]fluoranthene & $\mathrm{C}_{20} \mathrm{H}_{12}$ & 5 & 252.3 & 168.3 & $5 \times 10^{-7}\left(20^{\circ} \mathrm{C}\right)$ & 1.2 \\
\hline Benzo[a]anthracene & $\mathrm{C}_{18} \mathrm{H}_{12}$ & 5 & 228.3 & $158-162$ & $\begin{array}{l}2.2 \times 10^{-8} \\
\left(20^{\circ} \mathrm{C}\right)\end{array}$ & 10 \\
\hline Chrysene & $\mathrm{C}_{18} \mathrm{H}_{12}$ & 4 & 228.3 & $255-256$ & $6.3 \times 10^{-7}$ & 2.8 \\
\hline Pyrene & $\mathrm{C}_{16} \mathrm{H}_{10}$ & 4 & 202.1 & 156 & $2.5 \times 10^{-6}$ & 77 \\
\hline Fluoranthene & $\mathrm{C}_{16} \mathrm{H}_{10}$ & 4 & 202.3 & 108.8 & $5.0 \times 10^{-6}$ & $200-260$ \\
\hline Anthracene & $\mathrm{C}_{14} \mathrm{H}_{10}$ & 3 & 178.2 & 218 & $1.7 \times 10^{-5}$ & 700 \\
\hline Phenanthrene & $\mathrm{C}_{14} \mathrm{H}_{10}$ & 3 & 178.2 & 100 & $6.8 \times 10^{-4}$ & 1,200 \\
\hline Fluorene & $\mathrm{C}_{13} \mathrm{H}_{10}$ & 3 & 166.2 & $116-117$ & $\begin{array}{l}3.2 \times 10^{-4} \\
\left(20^{\circ} \mathrm{C}\right)\end{array}$ & 800 \\
\hline Acenaphthene & $\mathrm{C}_{12} \mathrm{H}_{10}$ & 3 & 154.2 & 95 & $4.47 \times 10^{-3}$ & 1,930 \\
\hline Acenaphthylene & $\mathrm{C}_{12} \mathrm{H}_{8}$ & 3 & 152.2 & $92-93$ & $\begin{array}{l}29 \times 10^{-3} \\
\left.{ }^{\circ} \mathrm{C}\right)\end{array}$ & 3,930 \\
\hline Naphthalene & $\mathrm{C}_{10} \mathrm{H}_{8}$ & 2 & 128.2 & 80.2 & $1.8 \times 10^{-2}$ & 30,600 \\
\hline
\end{tabular}

Since the PAHs are distributed between gas and particle bound phases, methods for the collection and analysis of them are separated into two groups:

i) for the collection of particle-phase PAHs fiber filters made of glass, quartz, teflon and other media are used. PAHs on the filter samples are extracted with techniques as reflux extraction, soxhlet extraction, microwave extraction, pressurized solvent extraction or ultrasonic extraction with a range of organic solvents such as hexane, dichloromethane, acetone and methanol individually or in combination.

ii) gas-phase PAHs are collected via pumped sampling because of their low concentrations in air, where a known volume of air is drawn through the sorbent such as polyurethane foam (PUF), XAD, Carbopack, Tenax TA, mixed sorbents and others. 


\section{Present study}

This study was focused on the development and validation of an Isotope Dilution - Gas Chromatography - Time of Flight - Mass Spectroscopy (ID-GC-TOF-MS) method by spiking PAHs onto thermal desorption tubes and investigation of the method sensitivity to the compounds found in biogas that are not present in other matrices such as ambient air. In this study, three compounds among 16 priority pollutant PAHs given in Table 1 were selected as representative: i) benzo[a]pyrene as it is carcinogenic and carries highest toxic load of any airbone PAH $[3,6]$; ii) benz[a]anthracene as it is carcinogenic and iii) naphthalene as it is the one with lowest molecular weight, melting point and highest vapour pressure at $25^{\circ} \mathrm{C}$. For the collection of PAHs, Tenax TA thermal desorption tubes were used. Tenax TA is a traditional sorbent (porous polymer) for trapping medium to high boiling compounds; it is especially useful for low concentrations because of its low background. Tenax TA is hydrophobic and it is suitable for PAHs.

Materials and Standards: PAHs were purchased commercially as highly pure solid (powder) standards and purities were determined in-house. Benz[a] anthracene was purchased from Supelco with product number 4-8563 and Lot\#LB95345V with stated purity of 98.9\% (GC-FID) and 99.5\% (HPLC UV-254 nm). Benzo[a]pyrene was purchased from Supelco with product number 4-8564 and Lot\#LB98566V with stated purity of 99.9\% (GC-FID) and 99.9\% (HPLC UV-254 nm). Naphthalene was purchased from Fluka with product\# 4-8564 and Lot\#BCBF9319V with stated purity of 99.9\% (GC-FID) by the company. Isotopically enriched standards were purchased from Cambridge Isotope Laboratories: benz[a]anthracene-d12 with product\#CIL DLM-610-0.1 and Lot\#PR-18301, benzo[a]pyrene-d12 with product number CIL DLM-258-0.1 and Lot\#1-15486, naphthalene-d8 with product number CIL DLM-365-5 and Lot\#PR-20618/07299NP1. All solvents used were GC-MS grade.

Main stock solutions (S1) were prepared individually by dissolving around $30 \mathrm{mg}$ of powdered solids in methanol, thus obtaining a mass fraction of $1000 \mu \mathrm{g} / \mathrm{g}(\mathrm{ppm})$ of the PAHs. From these stocks, secondary stock solutions (S2) and final mix-stock solutions S3-Native and S3-Internal Standard (IS) were prepared. Final S3 solutions were used for the preparation of calibration solutions.

Purity Assessment of Standards: The purity assessment of benzo(a)anthracene (Figure 1.), benzo(a)pyrene (Figure 2.), and naphthalene (Figure 3.) was done by qNMR. 1,3,5Trimethoxybenzene was used as IS and dimethylsulfoxide-D6 (Merck, 99.9\%) was used as solvent. 1,3,5-Trimethoxybenzene purity $(99.798 \pm 0.174) \%(k=2)$ was determined by UME CRM 1301 chloramphenicol [7] with a certified value of $(99.58 \pm 0.15) \%(k=2)$ (Figure 4.). Three individual sub samples were prepared for each analyte and each sample was analyzed with three repetitions.

The sample solution of analytes was prepared by following steps: benzo[a]anthracene, benzo[a]pyrene or naphthalene $(10 \mathrm{mg}-15 \mathrm{mg})$ and 1,3,5-Trimethoxybenzene $(10 \mathrm{mg}-15 \mathrm{mg})$ were accurately weighed, dissolved in DMSO-D6 $(1.0 \mathrm{~mL})$, stirred with vortex for 30 seconds and $0.7 \mathrm{~mL}$ solution transferred to a NMR tube. All NMR measurements were carried out on a Varian 600 spectrometer operating at $599.90 \mathrm{MHz}$. The probe used was a Varian's One NMR. The following parameters were employed for acquisition of spectra: spectral width, $16 \mathrm{ppm}$; acquisition time, $3.4 \mathrm{~s}$; relaxation delay, $40 \mathrm{~s} ; 90^{\circ}$ pulse width, $6.4 \mu \mathrm{s}$; time domain, $64 \mathrm{~K}$ data points; 32 scans; temperature, $298.15 \mathrm{~K}$.

All NMR spectra were processed with the software Mestrenova 10.0. An exponential line broadening window function of $0.3 \mathrm{~Hz}$ was used in the data processing. After Fourier transformation of the free induction decays, the spectra were baseline corrected, phased, and integrated in the appropriate region. The peaks for the analyte and the internal standard were integrated inside, that is, including, the ${ }^{13} \mathrm{C}$ satellites.

The equation for the calculation of purity in qNMR is as follows:

$$
P_{x}=\frac{I_{x}}{I_{S t d}} \frac{N_{S t d}}{N_{x}} \frac{M_{x}}{M_{S t d}} \frac{m_{S t d}}{m_{x}} P_{S t d}
$$


In the above equation, $\mathrm{I}_{\mathrm{Std}}, \mathrm{N}_{\mathrm{Std}}, \mathrm{M}_{\mathrm{Std}}, \mathrm{m}_{\mathrm{Std}}$ and $\mathrm{P}_{\mathrm{Std}}$ are the peak area, number of proton, molecular weight, mass and purity of the internal standard, respectively. $I_{x}, N_{x}, M_{x}, m_{x}$ and $P_{x}$ are the peak area, number of proton, molecular weight, mass and purity of the sample, respectively.

The calculation equation of the relative standard uncertainty is as follows:

$$
u\left(P_{x}=P_{x} \sqrt{\left(\frac{u\left(I_{x} / I_{s t d}\right)}{I_{x} / I_{\text {std }}}\right)^{2}+\left(\frac{u\left(M_{x}\right)}{M_{x}}\right)^{2}+\left(\frac{u\left(M_{s t d}\right)}{M_{s t d}}\right)^{2}+\left(\frac{u\left(m_{x}\right)}{m_{x}}\right)^{2}+\left(\frac{u\left(m_{\text {std }}\right)}{m_{\text {std }}}\right)^{2}+\left(\frac{u\left(P_{\text {std }}\right)}{P_{\text {std }}}\right)^{2}}\right.
$$

The uncertainty from balance is the most important component for the total uncertainty value so all of the samples were weighed with an advanced balance. The uncertainty from molecular weight is often pretty small than integration repeatability. All of the free induction decays of samples were processed by the same phase and baseline correction algorithms and used the same integral regions for the good repeatability.

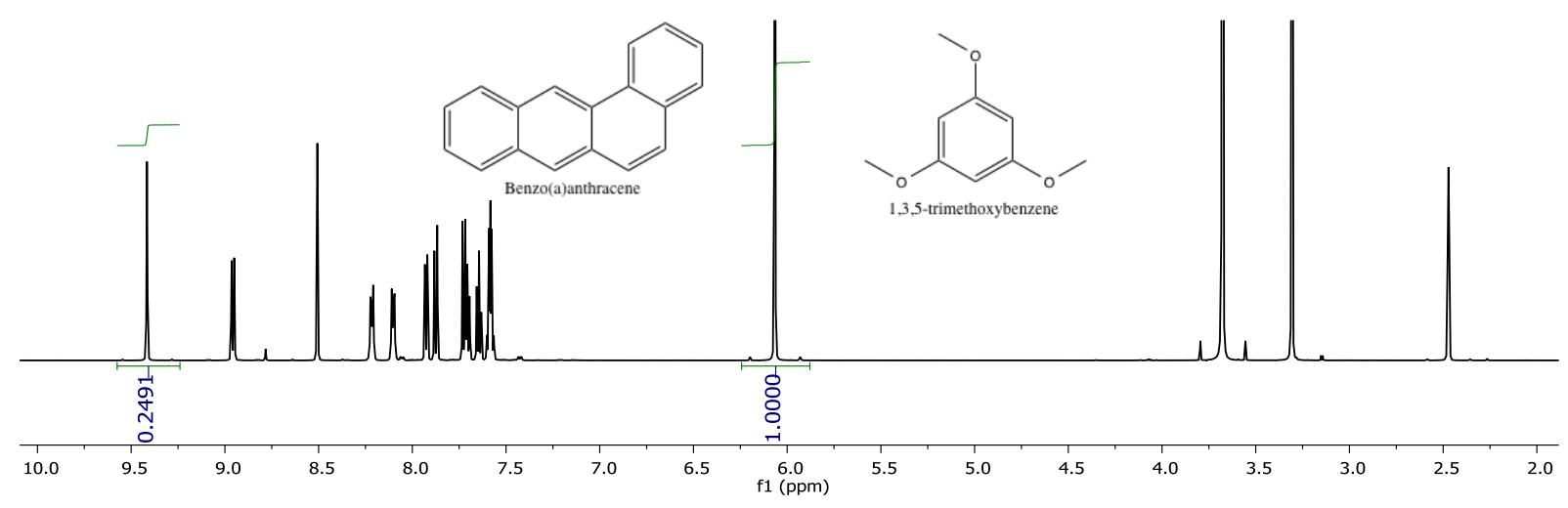

Figure 1. Benzo(a)anthracene ${ }^{1} \mathrm{H}$ QNMR spectrum

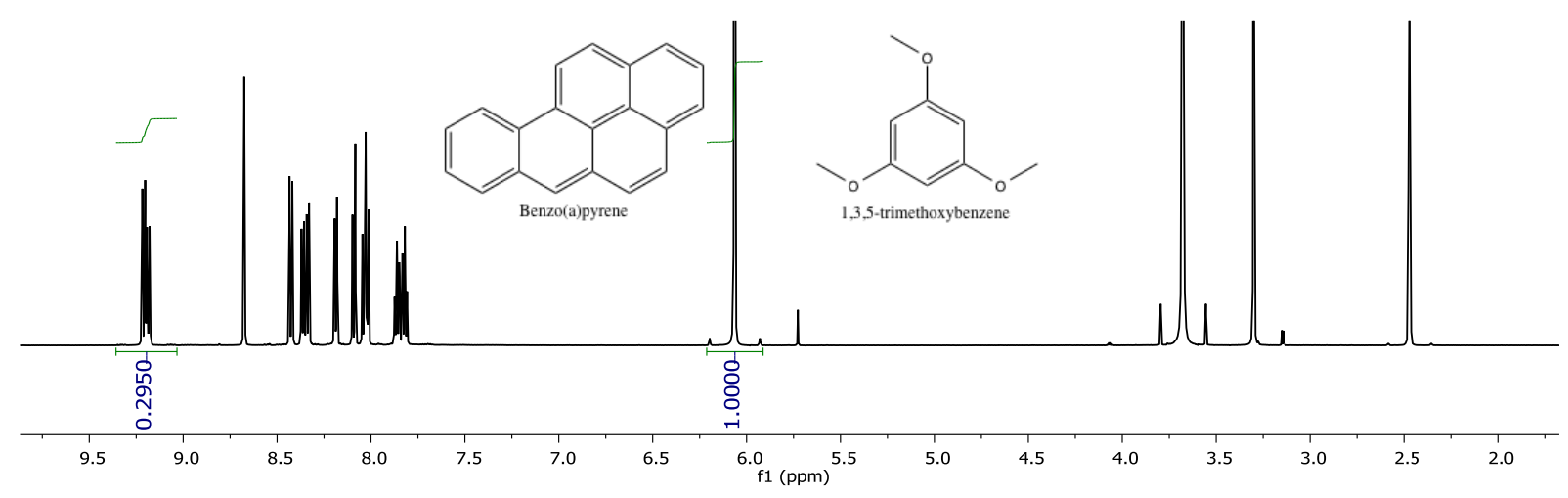

Figure 2. Benzo[a]pyrene ${ }^{1} \mathrm{H}$ QNMR spectrum 
Purities of the standards are given in Table 2.

Table 2. Purities, expressed as mass fractions, of standards determined by qNMR

\begin{tabular}{llll}
\hline Chemical & Method & Result $(\%)$ & Uncertainty $(\%) \mathbf{k = 2}$ \\
\hline Benz[a]anthracene & qNMR & 98.084 & 0.297 \\
Benzo[a]pyrene & qNMR & 94.118 & 0.517 \\
Naphthalene & qNMR & 99.901 & 0.220 \\
\hline
\end{tabular}

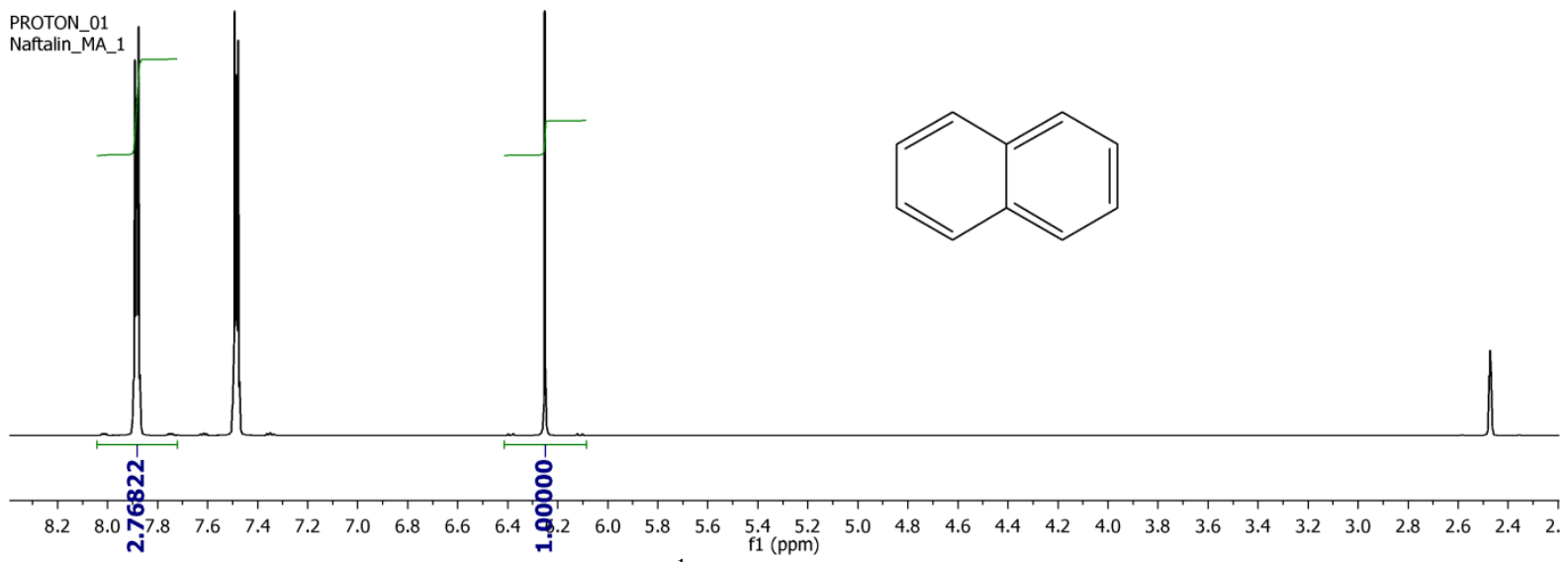

Figure 3. Naphthalene ${ }^{1} \mathrm{H}$ QNMR spectrum, IS:Maleic Acid

Analytical Instrumentation: For the method development, $1 \mu \mathrm{L}$ of calibration solutions were spiked onto Tenax TA thermal desorption tubes by gas tight syringe using CSRL and swept onto thermal desorption tube by the aid of air stream at a flow rate of $50 \mathrm{~mL} / \mathrm{min}$ for a period of $1 \mathrm{~min}$. PAHs adsorbed in Tenax TA tubes were desorbed by Perkin Elmer Turbo Matrix 350 ATD Thermal Desorber Instrument. Operating conditions of thermal desorber: tube temperature is $320{ }^{\circ} \mathrm{C}$, tube desorption time is $5 \mathrm{~min}$, trap temperature is from $-20{ }^{\circ} \mathrm{C}$ to $350{ }^{\circ} \mathrm{C}$, trap hold time is $5 \mathrm{~min}$, valve temperature is $225^{\circ} \mathrm{C}$, and transfer line temperature is $280^{\circ} \mathrm{C}$. The thermal desorption instrument was connected to a LECO PEGASUS HRT GC-TOF-MS instrument, where a TRV 5-MS $(30 \mathrm{~m} \times 0.25$ $\mathrm{mm} \times 0.25 \mu \mathrm{m}) \mathrm{GC}$ column was used with oven temperature programme of $90{ }^{\circ} \mathrm{C}(4 \mathrm{~min}), 80{ }^{\circ} \mathrm{C} / \mathrm{min}$ to $200{ }^{\circ} \mathrm{C}, 10{ }^{\circ} \mathrm{C} / \mathrm{min}$ to $300{ }^{\circ} \mathrm{C}(5 \mathrm{~min})$. The flow rate of carrier gas (helium) was $1 \mathrm{~mL} / \mathrm{min}$. MS source temperature was $250{ }^{\circ} \mathrm{C}$ and transfer line temperature was $280{ }^{\circ} \mathrm{C}$. MS ions used for the quantification are 128.062 for naphthalene, 136.110 for naphthalene-d8, 228.089 for benzo[a]anthracene, 240.167 for benzo[a]anthracene-d12, 252.090 for benzo[a]pyrene, and 264.165 for benzo[a]pyrene-d12.

Method Validation: In this study, isotope dilution mass spectrometry (IDMS) technique was used, For the method validation, linearity, repeatability, limit of detection (LOD) and limit of quantification (LOQ) parameters were determined. Linearity was evaluated using linear regression analysis of sixpoint calibration plot drawn by CurveExe program. Two independent calibration solution sets were prepared from stock solutions. The plots were consisted of three replicates per point. Squared correlation coefficients $\left(\mathrm{r}^{2}\right)$ for all analytes were found to be better than 0.99. Linear regression equations and correlation coefficients are given in Table 3. Method developed for PAHs was found to be linear in the range of $20 \mathrm{ng} / \mathrm{g}-500 \mathrm{ng} / \mathrm{g}$. The repeatability (determined in terms of relative standard deviation (RSD)) values were calculated using the corresponding peak area of three replicate analyses performed for each sample at the concentration of $500 \mathrm{ng} / \mathrm{g}$. RSD values of PAHs are given in Table 3. LOD and LOQ values were calculated from the ten replicate analyses performed with the standard solution prepared at the concentration of $10 \mathrm{ng} / \mathrm{g}$. LOD was determined as 3 times of standard 
deviation. LOQ was determined as 10 times of standard deviation. LOD and LOQ values determined for each PAH are given in Table 3.
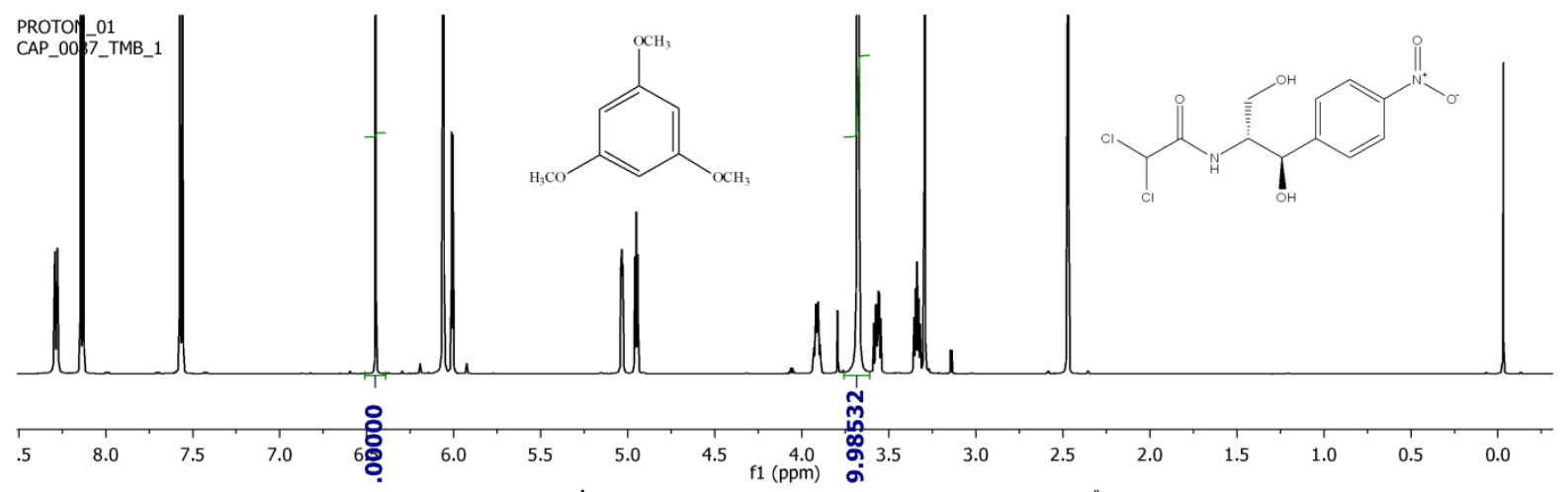

\section{data_PROTON_001
TMB_BA_Stok_1}
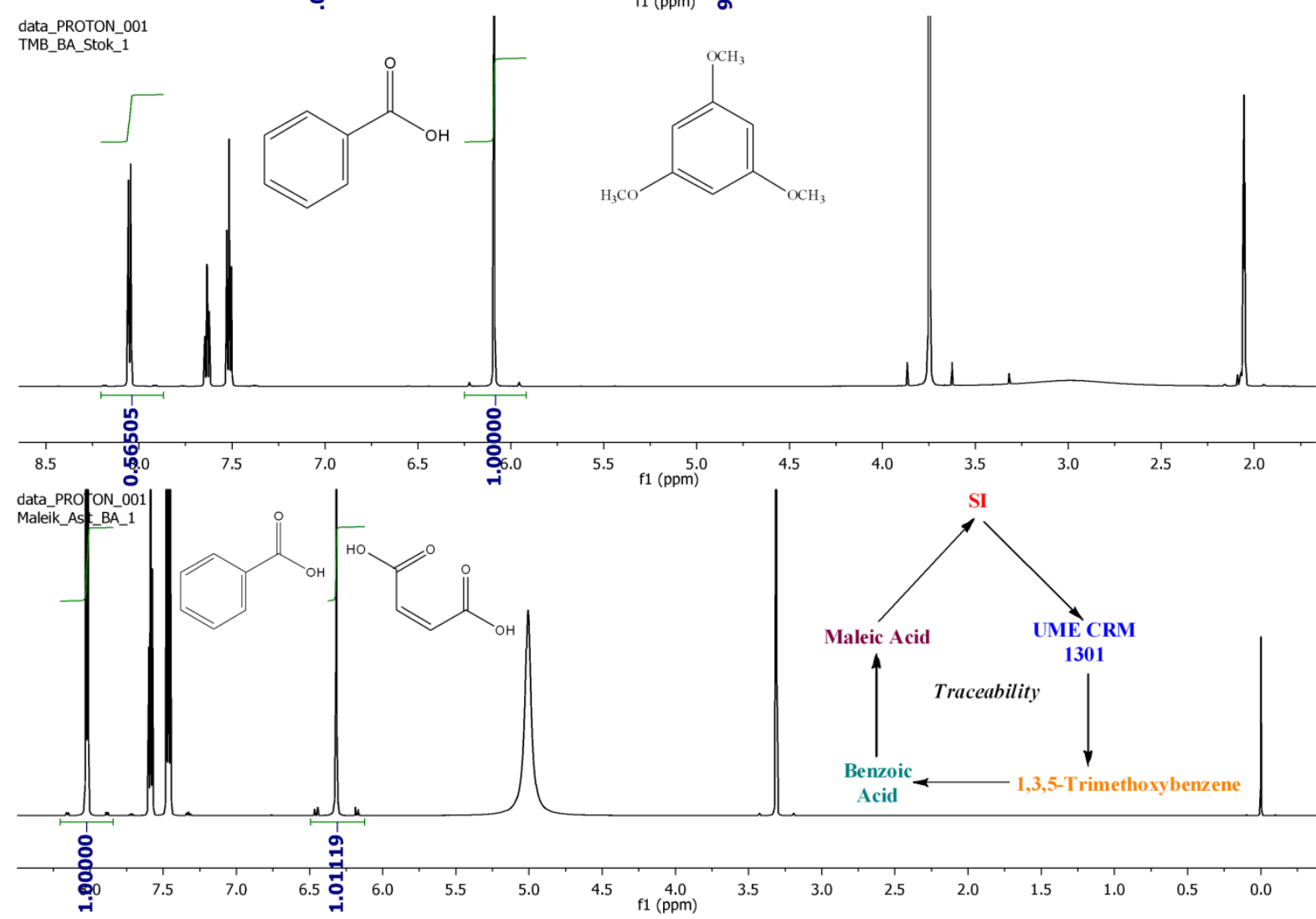

Figure 4. Traceability of TMB and Maleic acid with UME CRM 1301 chloramphenicol

Table 3. Validation parameters of ID-LC-TOF-MS method for PAHs

\begin{tabular}{|c|c|c|c|c|c|}
\hline Compounds & $\begin{array}{ll}\text { Linear } & \text { Regression } \\
\text { Equation } & \\
\end{array}$ & $\mathbf{R}^{2}$ & LOD (ng/g) & LOQ (ng/g) & $\begin{array}{l}\text { RSD } \\
(\%)\end{array}$ \\
\hline Naphthalene & $y=1.0022 x+0.0085$ & 0.9989 & 1.31 & 4.36 & 1.49 \\
\hline Benzo[a]anthracene & $y=0.9737 x+0.0041$ & 0.9993 & 4.03 & 13.43 & 0.94 \\
\hline Benzo[a]pyrene & $y=1.0142 x+0.0016$ & 0.9995 & 1.19 & 3.97 & 1.36 \\
\hline
\end{tabular}

Estimation of uncertainty: The uncertainty budget for the method developed was calculated according to EURACHEM/CITAC Guide [8]. The source of uncertainty budget consists of native stock solution preparation, IS-stock solution preparation, interpolation of the sample reading in the calibration graph and the spiking of the calibration solution. Maximum contribution to the uncertainty 
budget was arised from spiking of the calibration solution. Combined uncertainty budget formula is given below:

$$
\frac{u_{c(\text { Analyte })}}{c_{\text {Analyte }}}=\sqrt{\left(\frac{u\left(c_{I S S}\right)}{c_{I S S}}\right)^{2}+\left(\frac{u\left(c_{N S S}\right)}{c_{N S S}}\right)^{2}+\left(\frac{u\left(V_{S C S}\right)}{V_{S C S}}\right)^{2}+\left(\frac{u(C a l)}{C_{0}}\right)^{2}}
$$

Relative expanded uncertainties at $95 \%$ confidence level $(\mathrm{k}=2)$ were determined as $8.2 \%$ for naphthalene, $8.3 \%$ for benzo[a] anthracene and $8.3 \%$ for benzo[a]pyrene.

Effect of compounds found in biogas to the validated method: Effect of compounds found in biogas that are not present in other matrices such as ambient air were investigated against the validated method by spiking of $1 \mu \mathrm{L}$ of calibration solutions to Tenax TA thermal desorption tubes using CSLR as described above. For this purpose, a gravimetrically prepared biogas mixture consisting of $45 \%$ methane, $40 \%$ carbon dioxide and $15 \%$ nitrogen were used to sweep PAHs onto thermal desorber tube at a flow rate $50 \mathrm{~mL} / \mathrm{min}$ for one minute. The effect of gas amount was tested for 5,10 and 15 minutes of biogas flow through Tenax TA tubes injected with PAHs. Average recoveries for each compound were determined and given in Table 4.

Table 4. Average recoveries calculated for the method sensitivity test

\section{Recovery \%}

\begin{tabular}{lllllllll}
\hline Compound & $40 \mathrm{pg}$, & $80 \mathrm{pg}$, & $120 \mathrm{pg}$, & $160 \mathrm{pg}$, & $200 \mathrm{pg}$, & $80 \mathrm{pg}$, & $80 \mathrm{pg}$, & $80 \mathrm{pg}$, \\
& $1 \mathrm{~min}$ & $1 \mathrm{~min}$ & $1 \mathrm{~min}$ & $1 \mathrm{~min}$ & $1 \mathrm{~min}$ & $5 \mathrm{~min}$ & $10 \mathrm{~min}$ & $15 \mathrm{~min}$ \\
Naphthalene & $107 \%$ & $102 \%$ & $107 \%$ & $108 \%$ & $102 \%$ & $104 \%$ & $100 \%$ & $102 \%$ \\
Benzo[a]anthracene & $108 \%$ & $99 \%$ & $101 \%$ & $99 \%$ & $103 \%$ & $103 \%$ & $99 \%$ & $99 \%$ \\
Benzo[a]pyrene & $96 \%$ & $102 \%$ & $101 \%$ & $105 \%$ & $101 \%$ & $104 \%$ & $103 \%$ & $103 \%$ \\
\hline
\end{tabular}

Recoveries of these three selected PAH compounds in Table 4 are in the range of method uncertainties validated for PAHs in air. In the light of these findings, it appears that thermal desorption ID-GC-TOF-MS method developed for PAHs is not affected by the compounds found in biogas that are not present in other matrices such as ambient air. These findings can be a basis for a more detailed metrologically sound method development for polycyclic aromatic hydrocarbons in biogas.

\section{Acknowledgements}

This work has been developed within the EMRP project ENG54. This research received funding from the European Union on the basis of decision No 912/2009/EC and the participating countries within EURAMET (European association of National Metrology Institutes).

\section{ORCID}

Taner Gokcen: 0000-0003-3965-6704

Ahmet C Gören: 0000-0002-5470-130X

Tanil Tarhan: 0000-0003-4984-8873

Gokhan Bilsel: 0000-0002-5028-7068

Ilker Un: 0000-0001-5089-4602

Adriaan van der Veen: 0000-0002-9648-5123

\section{References}

[1] İ. Ün, B. Vatansever, A. Şimşek and A.C. Gören (2016). Comparison of qNMR and HPLC-UV techniques for measurement of Coenzyme $\mathrm{Q}_{10}$ in dietary supplement capsules, J. Chem. Metrol., 10(1), $1-10$.

[2] O.W. Awe, Y. Zhao, A. Nzihou, D.P. Minh and N. Lyczko (2017). A Review of Biogas Utilisation, Purification and Upgrading Technologies, Waste and Biomass Valorization., 8(2), 267-83.

[3] M. Raboni, V. Torretta, G. Urbini and P. Viotti (2015). Automotive shredder residue: A survey of the 
hazardous organic micro-pollutants spectrum in landfill biogas, Waste Manag. Res., 33(1), 48-54.

[4] S.M. Wandera, W. Qiao, D.E. Algapani, S. Bi, D. Yin, X. Qi, Y. Liu, J. Dach, R. Dong (2018). Searching for possibilities to improve the performance of full scale agricultural biogas plants, Renew. Energy., 116, 720-7.

[5] G. Urbini, P. Viotti and R. Gavasci (2014). Attenuation of methane, PAHs and VOCs in the soil covers of an automotive shredded residues landfill : A case study, J. Chem. Pharm. Res., 6(11), 618-25.

[6] S.K. Pandey, K.-H. Kim and R.J.C. Brown (2011). A review of techniques for the determination of polycyclic aromatic hydrocarbons in air, Trends Anal. Chem., 30(11), 1716-39.

[7] K. Topal, İ. Alper, A.C. Gören, M. Bilsel and İ. Ün (2014). Chloramphenicol Primary Calibrant UME CRM 1301 Certificate Report, 1-26.

[8] S.L.R. Ellison, M. Rosslein, A. Williams, L.A. Konopel'ko and A. V. Garmash (2003). EURACHEM/CITAC Guide: Quantifying Uncertainty in Analytical Measurement, J. Anal. Chem., $\mathbf{5 8}(2), 191$.

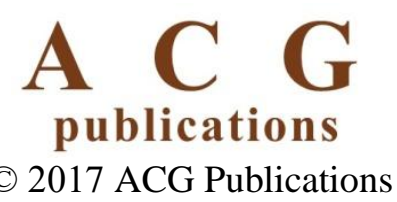

